4. Holleman DR Jr, Westman EC, McCrory DC, et al. The effect of sleeved arms on oscillometric blood pressure measurement. J Gen Intern Med I993;8:325-6.

5. Kahan E, Yaphe J, Knaani-Levinz H, et al. Comparison of blood pressure measurements on the bare arm, below a rolled-up sleeve, or over a sleeve. Fam Pract 2003;20:730-2.

6. Liebl M, Holzgreve H, Schulz M, et al. The effect of clothes on sphygmomanometric and oscillometric blood pressure measurement. Blood Press 2004;13:279-82.

7. Chobanian AV, Bakris GL, Black HR, et al. The seventh report of the Joint Nationa Committee on Prevention, Detection, Evaluation, and Treatment of High Blood Pressure. The JNC 7 Report. JAMA 2003;289:2560-72.

8. Padwal RS, Hemmelgarn BR, McAlister FA, et al; Canadian Hypertension Education Program. The 2007 Canadian Hypertension Education Program recommendations for the management of hypertension: part I - blood pressure measurement, diagnosis and assessment of risk. Can J Cardiol 2007;23:529-38.
9. Digital blood pressure monitor UA-767 [instruction manual]. Saitoma, Japan: A\&D Company. Available: www.aandd.jp/products/manual/medical/ua-767.pdf (accessed 2008 Jan. 2I)

Io. Gerin W, Schwartz AR, Schwartz JE, et al. Limitations of current validation protocols for home blood pressure monitors for individual patients. Blood Press Monit 2002;7:313-8.

Correspondence to: Prof. Donald W. McKay, Faculty of Medicine, Memorial University of Newfoundland, 300 Prince Philip Dr., Rm. H5359, St. John's NL AIB 3V6; fax 709 777-750I;

dmckay@mun.ca

\title{
Should physicians warn patients' relatives of genetic risks?
}

\section{Mireille Lacroix LLM, Gillian Nycum BCL LLB, Béatrice Godard PhD, Bartha Maria Knoppers PhD}

$\mathrm{W}$ hen a patient refuses to disclose genetic risk information to relatives, whether the patient's physician should or may disclose such information without the patient's consent will depend on the seriousness, the imminence and the preventability of the risk. The legal landscape around the duty to warn of genetic risk is unclear in Canada, but in some cases the benefits of disclosure may be so great as to outweigh the obligation to maintain confidentiality. In this article we use a case-based approach to address the ethical and legal issues surrounding physicians' duty to warn family members of genetic risk.

\section{The case}

Mrs. B has a family history of breast cancer and has become worried about getting cancer herself. Her family physician, Dr. T, refers her for genetic testing. Her results show that she has the BRCAI mutation.

Mrs. B attends post-test genetic counselling and clearly understands the implications of the results for herself and her daughter (aged 29), who is also Dr. T's patient. Dr. T receives a copy of the test results and strongly recommends that Mrs. B inform her daughter of her own risk, but Mrs. B declines to do so immediately. Dr. T offers to inform the daughter on Mrs. B's behalf, but Mrs. B declines the offer. The daughter is getting married in 6 months, and Mrs. B does not want to worry her. She says that she may tell her daughter herself after the wedding.

The daughter finds a pamphlet about a familial breast cancer program in her mother's study. During a visit with Dr. T, the daughter asks if she should be concerned.

\section{A conflict of duties}

Mrs. B's refusal to share her test results with her daughter places Dr. T in a dilemma. On one hand, the physician has a legal and ethical duty to Mrs. B to maintain confidentiality. On the other hand, the physician has a duty to take reasonable steps to prevent harm to her patients, to give them the in-

\section{Key points of the article}

- Protecting confidentiality and preventing harm to family members may create a dilemma for physicians.

- Requiring patients to agree to disclosure before genetic testing can lead to coercion and consequent reluctance to seek testing, which would effectively deprive patients and their relatives of genetic information.

- Physicians should make every effort to inform patients of the relevance of the information to relatives, persuade the patient of the need for intrafamilial disclosure and offer to inform relatives on behalf of patients.

- If patients refuse to have information disclosed, nonconsensual disclosure is not legally compelled and may in fact be punishable. However, if the risks are associated with a serious, imminent genetic condition that is preventable or treatable, the benefits of disclosure may be so great as to justify it on ethical grounds.

formation they need to make informed decisions about their care and to answer their questions to the best of her ability. ${ }^{1,2}$ Dr. $T$ also has a general ethical duty to act for the benefit of others. Do these latter duties amount to a duty to warn the daughter of her genetic risk? How can Dr. T square this duty with the confidentiality she owes to Mrs. B?

\section{Benefits and harms of nonconsensual disclosure}

The principal benefit of disclosing genetic risk information to family members is the avoidance of harm. If Dr. T informs Mrs. B's daughter of her risk of carrying the BRCAI mutation, the daughter will be able to decide whether to undergo testing

The authors are with the Centre de recherche en droit public, Université de Montréal, Montréal, Que., and are members of the Interdisciplinary Health Research International Team on Breast Cancer Susceptibility 
and take available preventive measures, including frequent and earlier screening and risk-reduction strategies. ${ }^{3}$ This information will also enable her to make more fully informed choices about her future, including decisions regarding marriage and career, as well as reproductive choices.

The disclosure of genetic risk information could also lead to harm. Going against Mrs. B's wishes shows disregard for her autonomy and moral integrity. In addition to undermining Mrs. B's trust in her family physician, this action could lead to mental and emotional distress for Mrs. B, as well as for her daughter, and could negatively affect their relationship.

At a societal level, a policy that authorizes breaches of confidentiality could have a negative impact on trust in health care professionals in general, which could compromise their ability to provide care. Over time, a discretionary power to override confidentiality could become a norm of practice and, therefore, be imperative rather than permissive. This would have significant implications for the therapeutic relationship, as it would fundamentally change the health care professional's role.

\section{Possible approaches to the dilemma}

Legislatures, agencies and organizations worldwide have articulated possible approaches to guide physicians in Dr. T's circumstances. ${ }^{4-6}$ These positions are summarized as follows:

Strict confidentiality: To maintain trust in the patientphysician relationship, physicians may not disclose genetic information to third parties without patient consent. Physicians fulfill their duty by informing patients of the importance of the information for family members and encouraging intrafamilial disclosure.

Duty to warn: Based on the principle of mutuality and the notion that, in genetics, the "patient is the family," physicians have an ethical duty to warn family members of genetic risk when patients refuse to do so. This ethical duty could evolve into a legal duty to disclose.

Informed consent: Before testing, physicians inform patients that, under specific circumstances, they will disclose relevant genetic information to family members if the patient refuses to do so. This approach gives patients the opportunity to accept these conditions, find another physician or forego testing. Although this approach may seem to respect patient autonomy, it may provide a theoretical choice only, given limited access to qualified professionals in many regions. Even in highly mobile populations, travelling to obtain genetic testing services could lead to family disruption. In practice, this approach may be coercive, leaving patients with the perception that they have no real choice.

Intermediate position: The patient's right to confidentiality must be respected as a general rule; however, nonconsensual disclosure of confidential information may be ethically permissible in exceptional circumstances: the seriousness of the harm, its preventability and the necessity of disclosure are key elements in the consideration. This is not a legal obligation, but an ethical justification and a possible legal defence against a claim of breach of confidentiality.
In the current case, a high risk of serious harm may be imminent (especially because Mrs. B's daughter is entering a high-risk age group for breast cancer onset if she has the $B R C A I$ mutation), and one that is associated with prophylactic and surveillance measures. Thus, the circumstances warranting disclosure in the intermediate position are arguably met. However, the Canadian legal landscape is less clear regarding the scope of the physician's duties and discretion in these circumstances.

\section{The legal landscape}

Two questions arise in an analysis of Canadian law around nonconsensual disclosure of genetic risk information: Do physicians have an obligation to warn at-risk individuals? If physicians do disclose patients' personal health information without consent, is their action legally defensible?

To date, no Canadian court has recognized a duty to warn in the context of genetics. However, this duty has been discussed in situations involving individuals infected with communicable diseases ${ }^{7}$ and psychiatric patients threatening violence. ${ }^{8}$ In such cases, the breach of confidentiality may be justified (i.e., there may be a legal defence to a claim for breach of confidentiality) to prevent harm to the public where the patient is an agent of the prospective harm.

A significant difference between these cases and cases involving genetic risk is that, in genetics, relatives are not potential victims of the patient's actions: at-risk relatives either carry a genetic mutation or they do not. Moreover, it is doubtful that the law of negligence or the civil law duty to rescue would be expanded to impose a duty in a situation such as Dr. T's. At the same time, because Mrs. B's daughter is also Dr. T's patient, the physician has a duty to answer her questions as fully as possible without breaching Mrs. B's confidentiality. If the daughter were not Dr. T's patient, the physician may still be justified in taking action to prevent harm to the daughter; however, it is doubtful that Dr. T would have a legal obligation to do so in that case, since there would be no physicianpatient relationship.

If the daughter's family history is complete in her own medical file, Dr. T could discuss the daughter's risks by referring to her family history without discussing her mother's case specifically. If the daughter's medical file does not contain a complete family history, Dr. T could encourage the daughter to take steps to complete her own family history by contacting her family members. The legality of disclosing the family history information in Mrs. B's medical record to the daughter may be as uncertain as is the disclosure of Mrs. B's genetic test information. If the daughter is concerned about her breast cancer risk, Dr. T could also suggest referral for genetic counselling and possibly testing.

The question of whether nonconsensual disclosure would be legally defensible butts heads with the legal duty of confidentiality (found in personal information protection laws, health statutes, institutional regulations, and civil and common law rules). The duty of confidentiality is not absolute: legal exceptions to it vary by jurisdiction but, in general, include circumstances in which there are paramount reasons 
for breaching confidentiality, such as when disclosure can limit or prevent a serious and imminent harm to an individual or group. Some genetic disorders for which tests are predictive and for which effective prevention and treatment measures are available may meet the criteria for disclosure. However, for common, multifactorial conditions, the information is probabalistic, and the timing, development and severity of disease expression also depends on other factors such as environment, lifestyle and gene-gene interactions. Therefore, only in exceptional circumstances will this type of genetic information reveal imminent harm.

\section{Conclusion}

Physicians should make every effort to inform patients of the relevance of the information to relatives, persuade the patient of the need for intrafamilial disclosure and offer to inform relatives on behalf of patients. If patients refuse to have information disclosed, nonconsensual disclosure is not legally compelled and may in fact be punishable. However, if the risks are associated with a serious, imminent genetic condition that is preventable or treatable, the benefits of disclosure may be so great as to justify it on ethical grounds.

This article has been peer reviewed.

Competing interests: None declared.
Contributors: All of the authors contributed to the conception and design of the article, critically revised the manuscript and approved the final version submitted for publication.

Acknowledgements: This research was funded by a Canadian Institutes of Health Research grant awarded to the Interdisciplinary Health Research International Team on Breast Cancer Susceptibility (INHERIT BRCAs) and was supported by Genome Canada/Genome Quebec.

\section{REFERENCES}

I. Canadian Medical Association. CMA code of ethics (update 2004). Ottawa: The Association; 2004. Available: http://policybase.cma.ca/PolicyPDF/PDo4-o6.pdf (accessed 2008 Jan 7)

2. Robertson G. Negligence and malpractice. In: Downie J, Caulfield T, Flood C, editors. Canadian health law and policy. 2nd ed. Toronto: Butterworths; 2002. p. 9I-IO9.

3. Horsman D, Wilson BJ, Avard D, et al. Clinical management recommendations for surveillance and risk-reduction strategies for hereditary breast and ovarian cancer among individuals carrying a deleterious BRCAI or BRCA2 mutation. J Obstet $G y$ naecol Can 2007;29:45-6o.

4. Knoppers BM. Genetic information and the family: Are we our brother's keeper? Trends Biotechnol 2002;20:85-6.

5. Godard B, Hurlimann T, Letendre M, et al. Guidelines for disclosing genetic information to family members: from development to use. Fam Cancer 2006;5:103-16.

6. Lacroix M, Godard B, Knoppers BM. Warning patients' relatives of genetic risks: policy approaches. GenEdit 2005;3:I-8. Available: www.humgen.umontreal.ca/int /GE/en/2005-3.pdf (accessed 2008 Jan 7).

7. Pittman Estatev. Bain (I994) II2 DLR (4th) 257 (Ontario Court [General Division]),

8. Smith v. Jones [1999] I SCR 455.

Correspondence to: Dr. Bartha Maria Knoppers, Université de Montréal, Bureau A-9430, Pavillon Maximilien-Caron, 3IOI, chemin de la Tour, Montréal QC $\mathrm{H}_{3} \mathrm{~T}_{\mathrm{IJ}} 7$; fax 5I4 343-2I22 